All letters must be typed with double spacing and signed by all authors.

No letter should be more than 400 words.

For letters on scientific subjects we normally reserve our correspondence column for those relating to issues discussed recently (within six weeks) in the BMF.

We do not routinely acknowledge letters. Please send a stamped addressed envelope if you would like an acknowledgment.

Because we receive many more letters than we can publish we may shorten those we do print, particularly when we receive several on the same subject.

\section{Surgeons and hepatitis B}

SIR, $-\mathrm{Mr}$ Stuart Kennedy's personal view, in which he describes his "elementary mistake" of submitting to a blood test for hepatitis, raises several issues, not least of which seems to be the management of the incident, which he describes as "the usual shambles that the NHS seems to revel in."

He mentions the various people who had a hand in managing his case: a houseman (took blood); a virologist (told him that he was a hepatitis B virus carrier and should stop operating temporarily); a senior physician (told him that there was no cluster of hepatitis B among his patients); colleagues (told him to have a viral DNA assay); the physician treating him (told him that he could plan his return to work); and his surgical colleagues (told him that he couldn't). No wonder he remains confused and resentful.

This case should have been dealt with from the start by the district's consultant occupational physician following the district's policy on carriage of hepatitis B virus. No single other person is likely to have experience of dealing with these cases, counselling skills, and the independence necessary to apply what is essentially a public health policy sympathetically to someone who may be a colleague. Managed better, this unfortunate case may well have had the same outcome but at least $\mathrm{Mr}$

\section{Hepatitis A immunisation}

SIR,-Dr Jane N Zuckermann and colleagues interpret their finding of a lower seroprevalence of hepatitis A IgG antibodies among first year medical students in 1991 than among blood donors and army recruits in 1988 as a dramatic decline in prevalence and attribute this to "improvement in socioeconomic conditions and personal hygiene."'

Implicit in this interpretation is the assumption that the important difference between these two samples is the three year period from 1988 to 1991. There are, however, other differences that are more likely to account for the variation in observed prevalence. The first of these is social class: medical students are drawn predominantly from middle class families whereas blood donors are likely to include a broader spectrum and army recruits are predominantly from working class families. Socioeconomic status has been shown to be associated with prevalence of antibodies to hepatitis A. ${ }^{2}$

The second concerns the age distribution of the samples. As IgG antibodies to hepatitis A virus persist for many years after infection, probably for life in most cases, ${ }^{3}$ the percentage of the population positive at any age represents the cumulative incidence of infection up to that age. Thus the older the sample tested the higher the expected prevalence. This is apparent in the higher preva-
Kennedy would be feeling better about it. There is life after stopping surgery, and in our experience high risk operators who are positive for hepatitis $\mathrm{Be}$ antigen have been redeployed happily in other fields of medicine.

Mr Kennedy's "streetwise" surgical colleagues were sharp enough to advise him (after the event) to refuse to be tested but not to advise him (before the event) to be immunised. He says that all the nurses had been immunised. Why hadn't the doctors been?

The Department of Health's guidance on employing health care staff infectious for hepatitis B virus is now well out of date, ${ }^{2}$ and in the absence of good occupational health advice the management of these cases will continue to be messy.

Incidentally, hepatitis B acquired occupationally is a prescribed industrial disease and sufferers are entitled to a modicum of no fault compensation.

DAVID SNASHALI MICHAEL PEEL IRA MADAN

Department of Occupational Health United Medical and Dental Schools of Guy's and St Thomas's Hospitals London SE1 7EH

1 Kennedy S. An elementary mistake? BMf 1991;302:1614. (29 June.)

2 Department of Health and Social Security. Hepatitis B and NHS staff. London: DHSS, 1981. (CMO (81) 11.)

lence reported in the whole sample of blood donors $(64 \cdot 4 \%)$ compared with that in young donors aged 18 to $30(57 \%)$. The age range of the first year medical students is given as 19 to 31 , which seems similar to that of the young blood donors (18 to 30 ); however, most of the students are almost certainly at the lower limit of the range and the blood donors more evenly distributed with respect to age.

Finally, even a major reduction in the incidence of hepatitis A infection would not have such a dramatic impact on IgG seroprevalence in such a short time as the seroprevalence is a measure of cumulative incidence and so reflects risk of infection over the lifetime of the individuals sampled and not just risk at the time of the sampling.

The interpretation provided by Dr Zuckermann and colleagues is not convincing because the social class and age distribution of their sample - and the dynamics of the infection-are not taken into account.

CLEONE I F ROONEY LAURA RODRIGUES

Department of Epidemiology and Population Sciences,

London School of Hygiene and Tropical Medicine,

London School of
London WC1 7HT

1 Zuckerman JN, Cockcroft A, Griffiths P. Hepatitis A immunis tion. BMY 1991;303:247. (27 July .)

2 Dienstag JL, Szumness W, Stevens CE, Purcell RH. Hepatitis A virus infection: new insights from seroepidemiologic studies. F Infect Dis 1978;137:328-40.

3 Hadler SC, Margolis HS. Viral Hepatitis. In: Evans AS, ed. Viral infections in humans. London: Plenum Medical, 1989

\section{Hepatitis A vaccine}

SIR,-Dr A J Tilzey and Professor J E Banatvala have outlined some of the current difficulties in controlling hepatitis $\mathrm{A}$ and the potential offered by hepatitis A vaccines.'

Recent experience in Liverpool emphasises the inadequacies of current means of control Altogether 313 cases of hepatitis A were notified in 1990 compared with 20 the previous year. This occurred despite efforts to control the disease including the dissemination of advice on hygiene and appropriate precautions to schools and parents; health education and health promotion activities done through the local media; and a circular sent to all general practitioners concerning controlling hepatitis $\mathrm{A}$ by giving human immunoglobulin to close contacts.

An investigation was undertaken in January 1991 to determine the mode of transmission of the infection in the city and to prevent further spread. Forty one cases were notified in that month. The age range of patients was 2 to 57 years, with 29 aged under 14 years and 23 aged 9 years or younger. Twenty one were male and 20 female. Two principal foci of illness were identified in deprived wards in the north and south of the city. Most patients had acquired the infection by person to person contact. Efforts to limit further spread of infection by using immunoglobulin were hampered by delays in notifying the consultant in communicable disease control. The median delay in notification was 10 days (interquartile range 7-20 days).

Long term control of hepatitis A depends on improvements in the knowledge and practice of hygienic principles. Whether passive immunisation is useful in controlling large outbreaks in the community is questionable. Hepatitis A vaccines have the potential to serve as an effective short term intervention, particularly if a group of susceptible subjects can be identified and targeted.

C MARTYN REGAN

Mersey Regional Health Authority,

Liverpool L36AL

Public Health Laboratory,

Fazakerley Hospital

Liverpool L97AL

QUTUB SYED

Liverpool Health Authority,

Liverpool L15 2HE

1 Tilzey AJ, Banatvala JE. Hepatitis A. BMJ 1991;302:1552-3. (29 June.)

\section{Routine testing for HIV at infertility clinics}

SIR,-Ms Susan Rice writes that the medical profession should not routinely test infertile 
couples for HIV because of the potential implications for obtaining life insurance cover and because fertility treatment may be withheld if this investigation is not done.' Since her letter was published we have become aware of a case in which screening for HIV yielded a positive result; this re-emphasises the need for routine screening, especially when the prevalence of HIV is increasing in society.

We routinely test for HIV for three reasons. Firstly, to "take account of the welfare of any child who may be born as a result of treatment, including the need of that child for a father (and mother)."' This applies to residents of the United Kingdom and to those living overseas. Secondly, because other professional bodies now recommend such screening. The BMA's representative body recently insisted that screening for HIV should be offered to all pregnant women, ${ }^{3}$ and the American Medical Association and the American government recommend HIV testing for all patients. ${ }^{+}$Thirdly, to protect the staff (both laboratory and medical staff) of fertility centres, who may handle potentially infective biological samples-for example, semen.

Attitudes towards AIDS and patients who are HIV positive must change, and the BMA and the government need to alter insurance companies' attitudes towards those screened for HIV otherwise infertile and pregnant women will be discriminated against.

We do not believe that AIDS should be regarded as a unique disease separate from other communicable diseases affecting pregnant women and their resultant children, whether the women conceive naturally or through assisted conception. In addition, it may be beneficial for patients who are HIV positive to be treated before the disease becomes apparent. Screening will help in this context.

We ask that infertile couples appreciate the underlying reasons why screening is in their best interests and the best interests of society. It would be ironic if a pregnancy resulting from assisted conception had to be terminated because HIV was detected in the prospective mother when preconception counselling and screening are available. It would also be regrettable if a child born after assisted conception treatment was left without appropriate support because one or both parents died of AIDS.

IAN CRAFT DAVID SHAPLAND TALHA AL-SHAWAF

\section{London Fertility Centre and Medicraft Services,}

London WIN IAF

1 Rice S. Routine testing for HIV at infertility clinics. $B M \mathcal{J}$ 1991;303:120. (13 July.)

2 Human Fertilisation and Embryology Authority. Code of practice: assessing clients, donors and the welfare of the child. London: HFEA, 1991:3.10.

3 The week in Inverness: testing pregnant women for HIV. $B M \mathcal{F}$ 1991;303:136. (13 July.)

4 Morris M. AMA rejects compulsory HIV testing. BMJ 1991; 303:77. (13 July.)

\section{Child sexual abuse and HIV infection}

SIR, - In his editorial on the consequences of child sexual abuse Professor Paul E Mullen listed some of the psychiatric problems common in people giving a history of sexual abuse in childhood.' Such a history is also common in people who present with psychological problems to our genitourinary medicine and HIV service. We are concerned that some of these patients may, in addition, have developed self destructive behaviour patterns, which in our experience makes them especially vulnerable to acquiring HIV infection.

Of 48 people with HIV infection referred to the clinic's psychology service in 1990, nine gave a history of child sexual abuse (penetrative inter- course or prolonged genital touching while they were under the age of 14). A common feature of these patients was their low self esteem and concomitant self destructive behaviour. This may not only contribute to a failure to adopt safer sexual practices and hence avoid HIV infection but also result in problems requiring clinical management. Such patients may also find it difficult to confront potentially painful situations and characteristically use denial or avoidance as a defence. Of 11 patients seen in 1990 whose behaviour put them at high risk of acquiring HIV infection but who declined testing, five gave a history of child sexual abuse.

Child sexual abuse is well known to be perpetuated by those who have been abused. This in combination with denial may mean that people who have acquired HIV infection and have a history of such abuse are more likely to continue to participate in high risk behaviour. Two cases illustrate this.

Case 1-A 28 year old woman who used intravenous drugs and had a history of child sexual abuse presented for an HIV test. Her boyfriend had AIDS, but despite knowing this she had continued to have unprotected intercourse with him and to share his needles, and she said that on one occasion she had injected herself with $15 \mathrm{ml}$ of his blood. She was shocked to be told that she was HIV positive and attempted suicide. Three months later she was pregnant after unprotected intercourse with a new partner.

Case 2-An 18 year old male prostitute requested an HIV test. He failed to keep the appointment to receive his result but was told that he had HIV infection when he attended subsequently with gonorrhoea. He had been brought up in care and said that he had been sexually abused by several workers in the children's home. Despite counselling about HIV he continued to have unprotected intercourse with multiple partners. Four years later he developed AIDS. His management was complicated by his denial, fear, and anger; his behaviour was chaotic, and he assaulted members of staff.

These observations are from a selected group of patients, and so it has been impossible to determine the true prevalence of a history of child sexua abuse in people with HIV infection. We intend to study this problem in greater depth and would be interested to hear if other centres are seeing a similar pattern.

MARY BURGESS JAN WELCH

Department of Genitourinary Medicine, St Giles Hospital,

1 Mullen PE. The consequences of child sexual abuse. $B M \mathcal{F}$ 1991;303:144-5. (20 July.)

\section{Consequences of child sexual abuse}

SIR,-In his editorial Professor Paul E Mullen discredits those who suggest that the long term effects of child sexual abuse are minimal. ' By doing so he is perpetuating an argument that is attractive to pragmatic doctors-namely, that the best argument against child sexual abuse is that it does harm. (He does this by drawing a parallel with the risks of drink-driving.) In my opinion this argument is flawed.

There is a proved association between sexual abuse in childhood and later psychiatric disorder, but the association may be due to confounders. It may be that adverse family and social factors predispose a child to both sexual abuse and adult psychiatric disorder. In a study of 796 college students Finklehor found that those students who reported having eight specific negative family and social factors had a $65 \%$ chance of having been sexually abused as children, and those with no risk factors had almost a $0 \%$ chance. ${ }^{2}$ These factors are all prime candidates for aetiological factors for adult psychiatric disorder-for example, absent mother, stepfather, etc.

It is important for doctors to realise that if a study was to show that childhood sexual abuse and adult psychiatric disorder were not causally associated the arguments against such abuse would in no way be threatened.

By way of illustration, if sexual intercourse between doctors and their patients was found not to cause any long term harm to patients this would in no way sway the General Medical Council, or most doctors, from the firm knowledge that it is morally wrong. The argument hinges on the nability of patients to give informed consent to have intercourse with their doctors. Because they give their trust to the doctor patients are believed to be in a vulnerable position and hence require the doctor's respect and protection.

The situation between adults and children is almost identical with this. Sexual contact between adults and children is morally and legally wrong because children are unable to give informed consent to it, and it is a child's legal right to be protected from sexual contact with adults.

If it is the psychiatric risks of sexual contact between adults and children that become the pillar on which it is outlawed the public will develop a stunted view of the rights of children. Also, any research that suggests that there is not a causal association between child sexual abuse and adult mental illness will needlessly threaten to dismantle the arguments against such abuse, and, lastly, much useful research may not be done or reported.

ANDREW J WIENER

Maudsley Hospital,

London SE5 8AZ

1 Mullen PE. The consequences of child sexual abuse. BMf 1991;303:144-5. (20 July.)

2 Finklehor D. Child sexual abuse: new theory and research. New York: Free Press, 1984

\section{Randomisation}

SIR, - We agree with Mr Douglas G Altman that a randomised, double blind controlled trial is the best method for evaluating treatment effects. ${ }^{1} \mathrm{We}$ fail to see, however, where a systematic bias can arise from allocation on the basis of odd and even birth dates. There seems to be a confusion here between allocation and blinding. If doctors are blind to the meaning of the allocation then such methods become an acceptable approximation to random allocation. If investigators are tempted to abuse allocation because they have knowledge of the next treatment then in a non-blinded trial they are able to do so, whether the method of allocation used is random or not. Only blindness to the treatment can remove this possibility altogether. If $\mathrm{Mr}$ Altman believes that there is a serious bias inherent to odd versus even birth dates he should say why.

The statement that such "inferior" methods are unacceptable to the $B M \mathcal{F}$ denies the reality of clinical research, where pure methods of randomisation may not be practicable. Although the evidence from non-blinded and non-randomised trials is weaker, to dismiss these efforts when the alternative may be no trial at all is draconian.

MICHAEL KING KHAVER BASHIR

Academic Department of Psychiatry,

Royal Free Hospital School of Medicine,

Royal Free Hospital

London NW $32 \mathrm{OG}$

1 Altman DG. Randomisation. BMf 1991;302:1481-2. (22 June.)

SIR,-In his editorial Mr Douglas G Altman suggests that using stratified randomisation may 